\title{
Extrahepatic Bile Duct Mixed Adenoneuroendocrine Carcinoma
}

National Cancer Institute

\section{Source}

National Cancer Institute. Extrahepatic Bile Duct Mixed Adenoneuroendocrine

Carcinoma. NCI Thesaurus. Code C96959.

A carcinoma that arises from the extrahepatic bile ducts and is characterized by the presence of a malignant glandular epithelial component and a malignant neuroendocrine component. At least 30 percent of either component should be present for the diagnosis to be made. 